\title{
Research on the Design Concept and Teaching of Computer Aided Design Software
}

\author{
Xiyang Zhang ${ }^{\text {a, }}{ }^{*}$, Yaohui Zheng ${ }^{b}$, Zhou Yan ${ }^{c}$, Meijuan Luan ${ }^{d}$ \\ School of Engineering Training Center, Shenyang Aerospace University, Shenyang, 110136, \\ China \\ a, *420484832@qq.com, b55186584@qq.com, c sdyanzhou16888@163.com, \\ d88454425@qq.com
}

\begin{abstract}
The Engineering training center is an important base to train the engineering quality and skill of university students, and it plays an important role in the university education. The ideological and political links of practical teaching are deeply studied and discussed, and the teaching results of Engineering Training Center are fully utilized to form a brand-new practical teaching form.
\end{abstract}

Keywords: Engineering Training; Modeling; Case Guide; Idea Development.

\section{Introduction}

\subsection{Course Description}

This course is a three-dimensional modeling training course, training students UG software threedimensional modeling ability, and can use UG software for independent design of three-dimensional modeling. In the traditional teaching process, we find that the contents of the teaching materials are old, the knowledge structure is unreasonable, and the allocation of class hours is unscientific, therefore, it is of great significance to explore the teaching reform of $\mathrm{Ug} 3 \mathrm{~d}$ modeling in a scientific, efficient and useful way. In UG modeling practice teaching, we should train the students from aesthetic ability to independent practice, arouse their learning interest, pay attention to practice teaching, and realize "Ability standard, knowledge and practice in one".

\subsection{Curriculum Advantages}

The practical teacher of this course is a key member of the ideological and political research team of the Engineering Training Center, and has been the instructor of the Party history study and education base of Shen hang for a long time.

\section{Instructional Design}

\subsection{Teaching Methods}

(1) case-based approach. " 2 " curriculum knowledge is "Root" and "Leaf", ideological and political elements are "Flower", deep-rooted leafy luxuriant flowers in full bloom, and finally bear rich frluits. Taking "Burr puzzle" as a teaching case, the background and principles of the project are shared to enable students to understand the wisdom of the ancient Chinese people.

(2) discussion teaching method. Teacher-student interaction is used in class to share the simple mortise-tenon structure and its application in real life. Set up questions and organize discussions to increase student participation.

(3)heuristic approach. Through the case inspired students to use their hands and minds, with different ways and means of Lu Ban lock design, assembly.

\subsection{Teaching Ideas}

Share before class. Engineering training course contains rich educational factors, through training practice teaching, to understand ancient Chinese civilization, to learn excellent traditional culture, to 
enhance engineering cognition. Through a comprehensive analysis of the work burr puzzle, we can train students'aesthetic ability, carry out aesthetic education, perfect their personality, improve their liberal education, and develop a healthy aesthetic taste and life style.

(1) the origin of the Lu Ban lock. Lu Ban lock originated in ancient Chinese architecture in the mortise and tenon structure, is the spring and autumn period in Lu Lu Ban's invention of a removable toy, later known as Lu Ban lock. The Traditional Lu Ban lock is composed of six cuboids, Kong Ming Lock does not need nails and rope, relying on its own structural connection support, seemingly simple, but condensed extraordinary wisdom.

(2) structural analysis. Lu Ban locks consist of blocks with different GROOVES, each of which has a tenon in the projection and a Mao in the recess. SMART design, high precision, by the size and shape are not the same through the convex and concave groove formed.

\section{After School Tasks}

Research structure to promote aesthetic consciousness. Study the design structure of Lu Ban lock, grasp the way of thinking, and apply it to the future three-dimensional modeling design. Lu Ban locks are assembled and disassembled in different ways. Design modeling and cultivation of innovative consciousness. The construction of the teaching staff is one of the important evaluation indexes to measure the construction level of the Engineering Company, and it is also the key to guarantee the quality of personnel training. Through the analysis and modeling of Lu Ban Lock, the 3D modeling design is carried out independently by UG software, and the design idea, work connotation and structure principle are expounded in detail. Train students to discover, propose, analyze and solve practical problems with the knowledge they have learned. Common Features and shortcuts. Master the shortcuts to common functions.

\section{Case Effectiveness}

\subsection{Significant Teaching Achievements}

UG three-dimensional software modeling training course, through the case-guided heuristic teaching, the final students can draw inferences, in the original six Lu Ban locks based on innovation and Development, design and development of the same four shapes, with an entirely different internal structure, the Lu Ban Lock Kit.

(1) prominent teaching significance: In the practical teaching of Engineering Training, the instructor communicates directly with the students, exercises most with the students, and carries out the ideological and political education work most easily. Teachers can make full use of effective resources and integrate their thoughts and spirits in the whole teaching process, which will play a role of supervision and encouragement to teachers' teaching attitude and work style.

(2) the students can feel the different effects of engineering training, let students realize that engineering training is not only in the face of heavy metal and tall equipment, but also can improve their own aesthetic.

\section{Case Study Review}

Education must first educate people and then educate talents. Student-centered practical teaching reform is an important part of the research and practice of new engineering of the Ministry of Education, and is also an inevitable trend of the reform and development of modern education and teaching. With the development and progress of society, we more and more deeply realize that the primary task of education is to educate people, and the second is to educate talents. Continue to dig deep training teaching methods. Engineering Training Ug software training courses to let the idea and technology organic combination, constantly innovative teaching methods. Do a good job of educating people for the Party and educating talents for the country. Let the students from the teacher's teaching 
attitude, Work Style and ideological and moral education by imperceptible. Continuing the course of ideological and political throughout, do a good job of high-quality, high-skilled personnel training.

\section{Acknowledgments}

This work was financially supported by 2021 Shenyang Aerospace University Typical teaching case project of Excellent Course Ideological and Political Education.

\section{References}

[1] Xue Zi Chuang. The reform and exploration of UG three-dimensional Modeling Course for Mould Specialty in Higher Vocational Colleges [J]. Heilongjiang Science. 2019(11): 62-63.

[2] Lui tung-ha. The teaching design and practice of introduction course from the perspective of ideological and Political Education. The chemistry of life. 2021(10): 2296-2301.

[3] You are as faithful as the letter. Research on engineering training practice and human model from the perspective of curriculum ideology and politics. Journal of Higher Education. 2021(19): 142-143.

[4] Pay The iron. Exploration and practice of construction of Engineering Training Center in the new era background [J]. Experimental Technology and management. 2020(11): 246-247.

[5] Chen Haijun. Integration of ideological and political education and practical teaching of Engineering Training [J]. Exploration of educational reform. 2021(5): 65-66.

[6] Paul wing-kit. Student-centered practice of exploratory teaching reform in new engineering course [J]. Laboratory Science. 2020(8): 140-141. 